\title{
Perceived work-related stress and early atherosclerotic changes in healthy employees
}

\author{
Joanna Bugajska $\cdot$ Maria Widerszal-Bazyl $\cdot$ Piotr Radkiewicz $\cdot$ Tomasz Pasierski • \\ Grażyna Anna Szulczyk • Jakub Ząbek • Bożena Wojciechowska • \\ Anna Jędryka-Góral
}

Received: 2 October 2007 / Accepted: 10 December 2007 / Published online: 3 January 2008

(C) The Author(s) 2007

\begin{abstract}
Objective This study was conducted to investigate the relationship between perceived work-related stress and preclinical atherosclerosis.

Methods A total of 100 managers and 50 office workers aged 35-65 participated in a questionnaire study. Individual, family and work-related stress risk factors and coping were evaluated in all the studied individuals. Serum levels of biochemical (total cholesterol, LDL, HDL, TG, glucose) and serological risk factors of atherosclerosis (anticardiolipin, anti- $\beta_{2}$ GPI, anti-oxLDL, anti-HSP and anti-hsCRP antibodies) were evaluated. A computer analysis of B-mode ultrasound images was used to assess carotid artery intima-media
\end{abstract}

\footnotetext{
J. Bugajska $(\bowtie) \cdot$ M. Widerszal-Bazyl · A. Jędryka-Góral

Department of Ergonomics,

Central Institute for Labour Protection-

National Research Institute, Czerniakowska 16,

00-701 Warsaw, Poland

e-mail: jobug@ ciop.pl

T. Pasierski · G. A. Szulczyk

Department of Coronary Artery Disease,

Institute of Cardiology, Warsaw, Poland

J. Ząbek

Department of Microbiology and Serology,

Institute of Rheumatology, Warsaw, Poland

B. Wojciechowska

Department of Diagnostics,

Institute of Rheumatology, Warsaw, Poland

P. Radkiewicz

Institute of Psychology, Polish Academy of Sciences,

Warsaw, Poland

A. Jędryka-Góral

Institute of Rheumatology, Warsaw, Poland
}

thickness (IMT) and atherosclerotic plaque in carotid arteries. Statistical analysis was conducted with SPSS v. 11.5.

Results The studied individuals showed average ranges of both the global stress level and of coping results. In $71 \%$ no changes were found in the ultrasound image and in $29 \%$ of individuals (43) the presence of plaque was shown. The mean value of the IMT measure was $0.0618 \pm 0.013 \mathrm{~mm}$. IMT and plaque correlated negatively with the level of global work-related stress $(r=-0.26 ; \quad P<0.01 ; \quad$ and $r=-0.28 ; \quad P<0.01 ;$ respectively). No correlation was found either between work-related stress and coping, or between coping and IMT $(P>0.05)$, or between workrelated stress and healthy lifestyle (no smoking, no excessive use of alcohol, high physical activity), or between healthy lifestyle and IMT $(P>0.05)$. Positive correlation between IMT and LDL and smoking did not result from higher stress reaction in the studied individuals.

Conclusions The explanation of the negative correlation between perceived work-related stress and preclinical atherosclerosis was not confirmed either by the subjects under high stress undertaking healthy protective activities or by their escaping into unhealthy behaviour. The most probable interpretation of the results is that in individuals with a low level of perceived work-related stress, somatization of stress takes place.

Keywords Work-related stress - Early atherosclerosis . Carotid arteries

\section{Introduction}

Stress can no longer be recognized as a problem of an individual only. Due to its versatile presence in every human's life, often resulting in health complications, stress has 
become a social problem and the role of work-related stress in this puzzle should not be underestimated. Coronary heart disease (CHD) is on the list of stress-related health problems.

Atherosclerosis, the basis of CHD, develops in a longlasting, multifactorial and complex process. In the etiopathogenesis of atherosclerosis, apart from traditional factors like lipids, carbohydrate metabolic disorders, hypertension and lifestyle (smoking, alcohol use and limited physical exercise), immunological disorders, as a consequence of reciprocal interactions in the psycho-neuroimmunological system, have been recently brought up (George and Shoenfeld 1997; Bednarska-Makaruk and Pasierski 2000; Kiecolt-Glaser and Glaser 1991; Amengual et al. 2001; Patryka et al. 2001; Jędryka-Góral et al. 2002; Jędryka-Góral 2003; Dinan 2005). Early atherosclerosis can even occur in young healthy people (Pasierski 1999).

For a long time now, occupational medicine has been interested in the relationship between work-related stress and CHD. Studies undertaken in this field have been based on western as well as eastern european populations (Jonsson et al. 1995; Hammer et al. 1998; Bosma et al. 1998, Kristenson et al. 1998; Kivimaki et al. 2002; Smith et al. 2005; Malinauskiene et al. 2005). Although there is a large body of literature on clinically overt CHD and its relation to workrelated stress, there have been very few studies on preclinical CHD in those circumstances (Lynch et al. 1997; Nordstrom et al. 2001; Rosvall et al. 2002; Hintsanen et al. 2005).

The current study aimed to fill this gap and to assess the relationship between work-related stress and preclinical atherosclerotic changes in healthy employees. We considered carotid artery intima-media thickening and/or plaque presence as a surrogate of coronary atherosclerosis. To detect these changes "gold-standard" methodology, i.e., Bmode carotid ultrasound examination, was applied. Because of the complex nature of the pathogenesis of CHD, other contributing factors have not been disregarded.

\section{Methods \\ Organization of the study}

First, all participants took part in a psychological study in which the level of stress and coping were evaluated with relevant questionnaires (see below). Then, the participants consecutively presented themselves for a clinical visit in which a medical examination took place and a blood sample was taken. Tests for biochemical parameters (see below) were performed on the same day as the blood sample was taken, according to routine laboratory procedures. Sera for immunological parameters (see below) were collected and stored according to international laboratory standards, then tested in runs (up to 40 sera per day) to minimize day-to-day variations.

\section{Participants}

One hundred healthy managers and 50 office workers ( $F: M=50: 50)$ aged 35-65 were studied. All of them were investigated for the presence of individual (age, obesity, hypertension, diabetes, smoking, alcohol use and low physical activity) and family (obesity, hypertension, diabetes, heart attack and stroke) risk factors for atherosclerosis. The studied individuals' detailed characteristics are presented in Table 1.

\section{Instruments}

Work-related stress was operationalized as perceived pressure caused by inappropriate working conditions. It was measured by the "Sources of pressure in your job" scale that is a part of the short version of the Occupational Stress

Table 1 Characteristics of studied groups

\begin{tabular}{|c|c|c|c|}
\hline & $\begin{array}{l}\text { Managers } \\
(n=100)\end{array}$ & $\begin{array}{l}\text { Office } \\
\text { workers } \\
(n=50)\end{array}$ & $\begin{array}{l}\text { Total } \\
(n=150)\end{array}$ \\
\hline Number & $50(50 \%)$ & $25(50 \%)$ & $75(50 \%)$ \\
\hline \multicolumn{4}{|l|}{ Females } \\
\hline Males & $50(50 \%)$ & $25(50 \%)$ & $75(50 \%)$ \\
\hline Age & $47.2 \pm 6.8$ & $50.16 \pm 6.46$ & $48.68 \pm 6.63$ \\
\hline \multicolumn{4}{|l|}{ Mean (years) } \\
\hline Minimum & 34 & 35 & 34.5 \\
\hline Maximum & 65 & 64 & 64.5 \\
\hline Individual risk factors & $26(26 \%)$ & $23(46 \%)$ & $49(32 \%)$ \\
\hline \multicolumn{4}{|l|}{ Hypertension } \\
\hline Obesity & $19(19 \%)$ & $17(34 \%)$ & $36(24 \%)$ \\
\hline Diabetes & $1(1 \%)$ & $1(2 \%)$ & $2(1.3 \%)$ \\
\hline \multicolumn{4}{|l|}{ Alcohol use } \\
\hline Every day & $3(3 \%)$ & 0 & $3(2 \%)$ \\
\hline $2-3 \times$ a week & $23(23 \%)$ & $2(4 \%)$ & $25(16.7 \%)$ \\
\hline Less & $69(69 \%)$ & $47(94 \%)$ & $116(77.3 \%)$ \\
\hline Never & $5(5 \%)$ & $1(2 \%)$ & $6(4 \%)$ \\
\hline Smoking cigarettes & $49(49 \%)$ & $30(60 \%)$ & $79(52.7 \%)$ \\
\hline $\begin{array}{l}\text { Hormone } \\
\text { replacement therapy }\end{array}$ & $8(8 \%)$ & $4(8 \%)$ & $12(8 \%)$ \\
\hline \multicolumn{4}{|l|}{ Physical activity } \\
\hline $2-3 \times$ a week & $26(26 \%)$ & $12(24 \%)$ & $38(25 \%)$ \\
\hline $1 \times$ in $7-10$ days & $32(32 \%)$ & $14(28 \%)$ & $46(30.7 \%)$ \\
\hline Less & $42(42 \%)$ & $24(48 \%)$ & $66(44 \%)$ \\
\hline Family risk factors & $41(41 \%)$ & $31(62 \%)$ & $72(48 \%)$ \\
\hline \multicolumn{4}{|l|}{ Hypertension } \\
\hline Obesity & $45(45 \%)$ & $23(46 \%)$ & $68(45.3 \%)$ \\
\hline Diabetes & $31(31 \%)$ & $12(24 \%)$ & $43(28.7 \%)$ \\
\hline Heart attack & $36(36 \%)$ & $21(42 \%)$ & $57(38 \%)$ \\
\hline Stroke & $30(30 \%)$ & $17(34 \%)$ & $47(31.3 \%)$ \\
\hline
\end{tabular}


Indicator (OSI-2) by Cooper et al. Widerszal-Bazyl's (2001) Polish adaptation of OSI-2 was used in the study. The scale consists of 40 items on potential sources of pressure at work; respondents are required to rate each source on six-point response scales, in which $1=$ it is very definitely not a source (of pressure) to $6=$ it is very definitely a source. Those 40 items were divided into eight subscales concerning the following stress factors: workload (e.g. "Having to work very long hours", "Taking work home"), relationships (e.g. "Inadequate guidance and backup from superiors", "Feeling isolated"), home-work balance (e.g. "Pursuing a career at the expense of home life"), recognition (e.g. "Underpromotion-working at a level below my level of ability"), organizational climate (e.g. "Characteristics of the organization's structure and design", managerial role (e.g. "Managing or supervising the work of other people"), personal responsibility (e.g. "Having to take risks"), hassle at work (e.g. "Attending meetings"). The scale made it possible to assess the global level of work-related stress (the sum of scores for all items) as well as to assess the level of a given kind of work stress, e.g. workload (the sum of scores for items related to workload). The reliability of the Polish version of the total scale was very high: Cronbach's $\alpha=0.95$. It was also satisfactory for most subscales: workload $\alpha=0.95$, relationships $\alpha=0.89$, home-work balance $\alpha=0.81$, recognition $\alpha=0.75$, organizational climate $\alpha=0.63$, managerial role $\alpha=0.57$, personal responsibility $\alpha=0.78$, hassle at work $\alpha=0.54$. (Widerszal-Bazyl 2001).

Coping was measured with the "How you cope with the stress you experience" scale that is also part of OSI-2, too. It consists of 10 items on potential coping strategies; respondents are required to rate the extent to which they actually use them as ways of coping with stress. Answers are given on six-point scales, from $1=\mathrm{I}$ never use it to $6=\mathrm{I}$ use it very extensively. Some coping strategies included into the scale dealt with coping through control (e.g. "Effective time management"), and some with coping through social support (e.g. "Talk to understanding friends"). The reliability of the Polish version of the total coping scale was Cronbach's $\alpha=0.70$, and reliability of its subscales: 0.70 (for coping through control) and 0.50 (for coping through social support). Therefore, the total index of coping was used in the analysis, as well as the index of coping through control.

Prior to the study, appropriate approval from the Local Ethics Committee was obtained. Participants were provided with detailed written information on the study's objectives and the methods that were going to be used; subsequently they signed their informed consent.

Serum levels of biochemical (total cholesterol, LDL, HDL, TG, glucose) and serological risk factors of atherosclerosis (anticardiolipin, anti- $\beta_{2}$ GPI, anti-oxLDL, antiHSP and anti-hsCRP antibodies) were evaluated.
Anticardiolipin antibodies Patients' sera were tested with ELISA for the presence of anticardiolipin antibodies, according to the modified Harris method (Luft et al. 1990). The results were presented as OD units. Reference ranges of aCL were established by studying sera from 100 healthy donors. The cut-off value was established as $\mathrm{OD}=x+4 \mathrm{SD}$ estimated for sera of healthy blood donors; it was 0.109 for the $\mathrm{IgG}$ class and 0.156 for the $\operatorname{IgM}$ class.

Anti- $\beta_{2}$ glycoprotein I ( $\beta_{2}$ GPI) antibody levels were measured with a commercial DIASTAM-FBGP 200 from Axis-Shield (Cat. No. FBG200) test. The results were expressed as OD units. Reference ranges of anti- $\beta_{2}$ glycoprotein I antibodies were established by studying sera from 152 healthy Caucasian donors (Axis-Shield Diagnostics Ltd. examination). The cut-off value was established as $\mathrm{OD}=0.195$.

Anti-HSP antibody levels (IgG class) were estimated with non-commercial methodology, after necessary modification, according to Tsoulfa et al. (1989), with the use of McLean reagents. The cut-off value was established as $x+$ 4SD estimated for sera of healthy blood donors; it was $\mathrm{OD}=0.423$. The estimation of IgM and IgA class antibodies was performed in the same manner.

Anti-oxLDL IgG antibody levels were measured with ELISA with the use of a commercial test from OLAB (Cat. No. BI-20032). The cut-off value was established as 200 arbitrary units.

hsCRP concentration was measured with ELISA with the use of commercial tests from EUCARDIO Laboratory Inc. (Cat. No. ZZ C4011E). The cut-off value was established as $4000 \mathrm{ng} / \mathrm{ml}$.

Intima-media thickness (IMT) and atherosclerotic plaque in carotid arteries were searched using a computer analysis of B-mode ultrasound images. Both carotid arteries were measured with a $7.5-\mathrm{MHz}$ linear-array transducer, part of Hewlett Packard Sonos. Plaque was defined as intima-medial thickening larger than 50\% in comparison to the surround area (Pignoli et al. 1986)

Statistical analysis of data was performed with SPSS v. 11.5. Means comparisons were carried out with a $t$ test for independent groups. In bivariate correlation analysis Pearson's $r$ coefficients were calculated. The level of significance was set at $\alpha<0.05$.

\section{Results}

Assessment of work-related stress

The level of work-related stress measured with OSI-2's Sources of pressure scale was as follows: managersmean $=154(\sigma=25)$, for office workers-mean $=145$ $(\sigma=28)$, for both groups-mean $=151(\sigma=25)$. According 
to Polish sten norms, the sten scale ("sten" stands for standard ten) consists of ten units. Each unit equals 0.5 of a standard deviation. It is, assumed that stens five and six means average results, stens seven to ten high results, and stens one to four low results (Canfield 1951). Developed for Polish managers (Widerszal-Bazyl 2001), the managers' mean falls on sten six, whereas the office workers' mean falls on sten five (Table 2). As a rule, stens five and six are interpreted as average results.

\section{Assessment of coping}

The level of coping measured with OSI-2's Coping scale was as follows: managers-mean $=40$, office workersmean $=38$, both groups - mean $=40$. According to Polish sten norms the managers' mean falls on sten five for men and on sten six for women. The office workers' mean falls on sten five (for both genders). Thus, it can be said that the coping results were in the average range.

\section{Laboratory findings}

The abnormality most frequently disclosed in biochemical findings were elevated levels of total cholesterol, LDL and triglycerides (in 52, 39 and 22\% of the studied individuals, respectively). Decreased levels of HDL and increased levels of glucose were less frequent and were found in $12 \%$ of cases each.

Of the immunological parameters studied, oxLDL antibodies were most frequently found (in $26 \%$ of cases), followed by an elevated level of hsCRP (in $11 \%$ of cases). In a few cases antibodies to $\beta_{2}$ GPI and HSP-65 (IgG class) were found (in $1 \%$ and $3 \%$ of studied cases, respectively). None of the studied individuals was positive for aCl. For six sera which were borderline or positive for HSP-65 IgG class, IgM and IgA class antibodies were searched. Only in three cases were the results weakly positive (two in IgM and one in IgA class).

\section{Ultrasound examination of carotid arteries}

Changes in the ultrasound examination of carotid arteries confirming the presence of early atherosclerosis are shown in Table 3. Plaque was found in 43 (29\%) cases: in 26 man-

Table 2 Results of psychological examination

\begin{tabular}{lllllllll}
\hline Studied groups & \multicolumn{2}{l}{ Work-related stress } & & & \multicolumn{2}{l}{ Coping } \\
\cline { 2 - 3 } & Mean & Stens & & & Mean & \multicolumn{2}{l}{ Stens } & \\
\hline Managers & 154 & 6 & 6 & 40 & 5 & 6 \\
Office workers & 145 & 5 & 5 & 38 & 5 & 5 \\
Total & 151 & 6 & 5 & 40 & 5 & 6 \\
\hline
\end{tabular}

Table 3 Results of ultrasound examination of carotid arteries in studied groups

\begin{tabular}{llll}
\hline & $\begin{array}{l}\text { Managers } \\
(n=100)\end{array}$ & $\begin{array}{l}\text { Office } \\
\text { workers } \\
(n=50)\end{array}$ & $\begin{array}{l}\text { Total } \\
(n=150)\end{array}$ \\
\hline $\begin{array}{c}\text { Number of individuals } \\
\text { without changes }\end{array}$ & $74(74 \%)$ & $33(66 \%)$ & $107(71 \%)$ \\
$\begin{array}{c}\text { Number of individuals } \\
\text { with plaque }\end{array}$ & $26(26 \%)$ & $17(34 \%)$ & $43(29 \%)$ \\
$\begin{array}{c}\text { Intima-media } \\
\text { measurement values }\end{array}$ & $0.0620 \pm 0.014$ & $0.0610 \pm 0.0120 .0618 \pm 0.013$ \\
\hline
\end{tabular}

agers (26\%) and in 17 office workers (34\%); groups did not differ statistically. The distribution of the mean values of the IMT measure was slightly skewed to the right. The mean values of IMT in managers and office workers were $0.0620 \pm 0.014$ and $0.0610 \pm 0.012 \mathrm{~mm}$, respectively; groups did not differ statistically.

Correlation between IMT and the presence of plaque in carotid arteries with atherosclerosis risk factors

Positive correlation was found between IMT and age $(r=0.42 ; P<0.001)$, diastolic blood pressure $(r=0.20$; $P<0.05)$, LDL $(r=0.28 ; P=0.001)$, anti-HSP antibodies $(r=0.24 ; P<0.05)$, whereas negative correlation was revealed with $\mathrm{aCl}-\operatorname{IgG}(r=-0.20 ; P<0.05)$ and global work-related stress level $(r=-0.26 ; P<0.01)$. Among the stressors studied, statistical significance was shown for interpersonal relations $(r=-0.23 ; P<0.00)$, work-home balance $(r=-0.19 ; P<0.05)$, managerial role $(r=-0.24$; $P<0.01)$ and organization climate $(r=-0.22 ; P<0.01)$. The presence of plaque correlated positively with age $(r=0.42 ; P<0.001)$, smoking $(r=0.18 ; P<0.05)$, LDL $(r=0.30 ; P<0.01)$ and negatively with global workrelated stress level $(r=-0.28 ; P<0.01)$. Statistical significance was shown for the following stressors: work load $(r=-0.24 ; P<0.01)$, interpersonal relations $(r=-0.18$; $P<0.05)$, work-home balance $(r=-0.33 ; P<0.01)$ and responsibility $(r=-0.25 ; P<0.01)$ (see Table 4$)$.

Correlation between LDL/smoking and global stress level

Pearson's analysis showed a negative relation between LDL and global stress level $(r=-0.17 ; P<0.05)$, and between smoking and global stress level $(r=-0.17$; $P<0.05)$.

Work-related stress, coping, lifestyle and IMT

Pearson's analysis was performed in two triangles: (a) work-related stress-coping-IMT, and (b) work-related stress-healthy lifestyle-IMT. No statistically significant 
Table 4 Correlations between IMT and the presence of plaque in carotid arteries and atherosclerosis risk factors (Pearson's $r$ )

\begin{tabular}{|c|c|c|}
\hline Risk factor & IMT & Plaque \\
\hline Age & $0.42 * *$ & $0.43 * *$ \\
\hline BMI & 0.12 & 0.04 \\
\hline Systolic blood preasure & 0.13 & 0.06 \\
\hline Diastolic blond preasure & $0.20 *$ & 0.10 \\
\hline Cigarette smoking & 0.13 & $0.18 *$ \\
\hline Physical activity & -0.02 & 0.07 \\
\hline LDL & $0.28 * *$ & $0.30 * *$ \\
\hline HDL & -0.16 & -0.05 \\
\hline Triglycerides & 0.04 & 0.05 \\
\hline Glucose & 0.08 & 0.02 \\
\hline hsCRP & 0.05 & 0.02 \\
\hline Anti-HSP & 0.16 & 0.19 \\
\hline $\mathrm{aCl}-\mathrm{IgG}$ & $-0.20 *$ & -0.10 \\
\hline $\mathrm{aCl}-\mathrm{IgM}$ & -0.14 & -0.15 \\
\hline Anti-oxLDL & -0.10 & -0.17 \\
\hline Workload & -0.15 & $-0.24 * *$ \\
\hline Relationships & $-0.23 * *$ & $-0.18 *$ \\
\hline Home-work balance & $-0.19 *$ & $-0.33 * *$ \\
\hline Managerial role & $-0.24 *$ & -0.14 \\
\hline Personal responsibility & -0.14 & $-0.25 * *$ \\
\hline Hassle at work & -0.11 & -0.14 \\
\hline Recognition & $-0.25^{* *}$ & -0.15 \\
\hline Organizational climate & $-0.22 * *$ & -0.15 \\
\hline Total index of coping & -0.12 & -0.01 \\
\hline Coping through control & -0.05 & 0.02 \\
\hline Global level of stress & $-0.26 * *$ & $-0.28 * *$ \\
\hline
\end{tabular}

* Correlation is significant at 0.01 (2-tailed)

** Correlation is significant at 0.05 (2-tailed)

relations were shown either between work-related stress and coping, or between coping and IMT $(P>0.05)$, or between work-related stress and healthy lifestyle (no smoking, no excessive use of alcohol, high physical activity), or between healthy lifestyle and IMT $(P>0.05)$.

\section{Discussion}

A multidisciplinary approach to assessing risk factors for atherosclerosis was considered by us in an earlier study (Jędryka-Góral et al. 2006). On the basis of a deep multilevel analysis we were able to show that in healthy individuals, as in CHD patients, individual and biochemical risk factors were likely to play a leading role in the development of early atherosclerosis. Psychosocial stress should also be considered; however, inflammatory-immunological factors have not been found to be an independent predictor.
As inflammatory-immunological factors, antibodies to oxLDL and HSP-65, hsCRP as well as anticardiolipin and anti- $\beta_{2}$ GPI antibodies were considered. In the extensive literature of the subject, these parameters are recognized as directly involved in the pathogenesis of atherosclerosis (George and Shoenfeld 1997; Kiecolt-Glaser, Glaser 1991; Amengual et al. 2001; Patryka et al. 2001; Jędryka-Góral et al. 2002; Jędryka-Góral 2003).

The present study was undertaken to extend the investigation of psychosocial stress and atherosclerosis. We looked in depth for correlation between preclinical atherosclerosis and work-related stress; correlations with other risk factors of $\mathrm{CHD}$ were done in parallel.

As expected, we found correlation between IMT and age, diastolic blood pressure, LDL and anti-HSP antibodies, and correlation between plaque and age, smoking and LDL.

Surprisingly, our results revealed that early atherosclerotic changes negatively correlated with the level of global job strain and some of its components (interpersonal relations, work-home balance, managerial role, organization climate-for IMT; work load, interpersonal relations, work-home balance, responsibility-for plaque).

Ambiguous results have been previously reported in other, although very few, studies where work, psychosocial factors and carotid atherosclerosis were studied with ultrasound. Rosvall et al.'s (2002) hypothesis that work-related stress characterized by high psychological demands and low decision latitude was associated with increased carotid atherosclerosis could not be confirmed either for women or for men. On the other hand, Lynch et al.'s (1997) prospective study showed that men who experienced work-related stress (demanding work and low economic rewards) had significantly greater progression of carotid atherosclerosis than more advantaged men. Hintsanen et al. (2005) provided data that job strain (a joint effect of job demands and job control) was associated with increased IMT in men but not in women. Similarly, Nordstrom et al. (2001) showed that in men with greater work-related stress (workplace demands and intrusion of work concerns into home life) the risk of focal lesions or intima-media thickness in coronary artery increased, whereas in women stress was not related to the prevalence of early atherosclerosis. Hlatky et al. (1995) disclosed that job strain (high psychological demands and low decision latitude) did not correlate with the presence of coronary disease in angiography, either for men or for women.

By searching for a relationship between work-related stress and atherosclerosis, we wanted to prove that the correlation found between early atherosclerotic changes and LDL and smoking is, at least partly, caused by a higher stress reaction in the studied individuals. It was assumed that individuals with a level of high stress undertook 
unhealthy behaviour: smoking or excessive food intake. However, for both LDL and smoking the correlation with stress was negative. One should keep in mind that only $39 \%$ of the studied individuals had elevated levels of LDL and $47 \%$ reported smoking. Therefore, these results should be interpreted causally.

We explored in depth the negative correlation we found between IMT and the presence of plaque, and the level of work-related stress. Being aware that OSI-2 measured perceived stress, another hypothesis was formulated; persons with a high level of work-related stress (conscious stress) undertake preventive activities at the level of coping or healthy lifestyle.

Perceived work-related stress as a risk factor for a clinically overt CHD has been investigated in multiple studies. Some prospective studies showed an association of workrelated stress with an incidence of CHD (Bosma et al. 1998; Kivimaki et al. 2002; Kivimaki et al. 2005); whereas others did not (De Bacquer et al. 2005; Rosvall et al. 2002; Eaker et al. 2004). The largest INTERHEART study covering 11119 cases and 13648 controls from 52 different countries all over the world confirmed this association with regard to work, home, financial and major life stress (Rosengren et al. 2004). There are studies which, indicated that perceived work-related stress had profound impact on internal organs, sensual organs, the locomotor system and skin health problems (Cheng et al. 2001; Lindgren et al. 2002).

In the literature of the subject, coping is closely linked to stress. The most common meaning of coping is, an effort to solve problems and to seek reduction of tolerance to stress. The CATS theory (cognitive activation theory of stress) offered a new approach to coping (Ursin, Eriksen 2004; Eriksen et al. 2005). This theory assumed two cognitive reformulations of the learning theory (stimulus-stimulus learning $=$ classical conditioning and response learning $=$ instrumental conditioning). Both reformulations are essential to understanding the relationship between learning, activation and relations between stress and health. The stress response (an alarm in the homeostatic system) results in behaviors that aim to cope with a situation. The level of alarm depends on what outcome of a stimulus is expected and the specific responses available for coping. Response outcome expectancy might be positive (coping), negative (hopelessness) or none (helplessness). Hence, coping defined as acquired positive outcome expectancy has some predictive value for stress and health.

According to Weidner and Cain (2003) research on how people cope with stress situations disclosed avoidant mechanisms (denial, distraction, excessive alcohol consumption) in men, whereas more cardioprotective strategies (depression, asking for help)—in females.

Stress management goes far beyond coping strategies. Toobert et al.'s (2002) results disclosed success of a complex intervention program to reduce CHD risk, which included improvement of diet, stress management, social support, smoking and physical activity.

In our study on preclinical atherosclerosis and workrelated stress, we were not able to confirm the hypothesis about the above-mentioned prophylactic activities. An analysis of correlation showed no significant relations between work-related stress and coping, between coping and IMT, between work-related stress and healthy lifestyle, or between healthy lifestyle and IMT.

A relatively novel conception was presented by de Lange et al. (2005), who claimed that the relationship between stressful work and psychological well-being may be reciprocal. Their results showed that mental health might influence employees' perceived work characteristics. It is likely that the employees in our study had been recruited from that part of working society who felt fit to undertake ambitious tasks of managers and office workers and who developed job adaptive mechanisms over time.

The most probable interpretation of the negative correlation between perceived work- related stress and preclinical atherosclerosis is that in the case of individuals with a low level of perceived work-related stress, somatization of stress took place, i.e., stress is not perceived at the conscious level but it leads to somatic effects (e.g., IMT).

We are aware of some limitations of our study. Firstly, the results regarding work-related stress were based on self-reported data, which per se could always be a matter of some bias. Secondly, the number of employees studied was limited to 150 . Voluntary participation of employees and fully unselected method of recruitment can guarantee the objectivity of the results. Thirdly, it was a cross-sectional study. A prospective type of research on risk assessment is preferable nowadays. However, our study did not aim to assess risk of CHD but to find correlation between work-related stress and early atherosclerosis, so we believe the measure taken for this purpose was appropriate.

We are more than convinced that to achieve full understanding of negative correlation between work-related stress and early atherosclerosis requires further interdisciplinary studies and we would be happy to continue exploration into this intriguing field.

Acknowledgement This study was a part of research task No. IV-903 of the National Programme "Adaptation of working conditions in Poland to EU standards" financed by the State Committee for Scientific Research of Poland in 2002-2004. The Central Institute for Labour Protection-National Research Institute was the Programme's main co-ordinator.

Open Access This article is distributed under the terms of the Creative Commons Attribution Noncommercial License which permits any noncommercial use, distribution, and reproduction in any medium, provided the original author(s) and source are credited. 


\section{References}

Amengual O, Atsumi T, Khamashta MA, Hughes GRV (2001) Antiphospholipid syndrome and atherosclerosis. In: Shoenfeld Y, Harats D, Wick G (eds) Atherosclerosis and autoimmunity. Elsevier, Amsterdam

Bednarska-Makaruk M, Pasierski T (2000) Role of cholesterol in pathogenesis and prevalence of vasculopathie) (in Polish). In: Żurek I, Stuczyńska G (eds) Statins. Medycyna Praktyczne, Kraków

Bosma H, Peter R, Siegrist J, Marmot M (1998) Two alternative job stress models and the risk of coronary heart disease. Am J Public Health 88:68-74

Canfield AA (1951). The "ten" scale-a modified C-scale. Educ Psychol Meas 11:295-297

Cheng Y, Guo YL, Yeh WY (2001) A national survey on psychosocial job stressors and their implications for health among working people in Taiwan. Int Arch Occup Environ Health 74:495-504

De Bacquer D, Pelfrene E, Clays E, Mak R, Moreau M, de Smet P, Kornitzer M, DeBacquer G (2005) Perceived job stress and incidence of coronary events: 3-year follow-up of the belgian job stress project cohort. Am J Epidemiol 161:434-441

de Lange A, Taris TW, Kompier MAJ, Houtman ILD, Bongers PM (2005) Different mechanisms to explain the reversed effects of mental health on work characteristics. Scand J Work Environ Health 31:3-14

Dinan TG (2005) Vasopressin: the neglected target for stress modulation? Stress Health 21:145-146

Eaker ED, Sullivan LM, Kelly-Hayes M, D’Agostino RB Sr, Benjamin EJ (2004) Does job strain increase the risk for coronary heart disease or death in men and women?: the framingham offspring study. Am J Epidemiol 159:950-958

George J, Shoenfeld Y (1997) The anti-phospholipid (Hughes) syndrome: a crossroads of autoimmunity and atherosclerosis. Lupus 6:559-560

Hammar N, Alfredson L, Johnson JV (1998) Job strain, social support at work and incidence of myocardial infarction. Occup Environ Med 55:548-553

Hintsanen M, Kivimaki M, Elovainio M, Pulkki-Raback L, Keskivaara P, Juonala M, Raitakari OT, Keltikangas-Jarvinen L (2005) Job strain and early atherosclerosis: the cardiovascular risk in young Finns study. Psychosom Med 67:740-747

Hlatky MA, Lam LC, Lee KL, Clapp-Channing NE, Williams RB, Pryor DB, Califf RM, Mark DB (1995) Job strain and the prevalence and outcome of coronary artery disease. Circulation 92:327-333

Jędryka-Góral A, Maśliński W, Ziółkowska M, Konarska M, Żołnierzyk-Zreda D (2002) Stress-where are we now? Does immunity play an intrinsic role? Autoimmunity 35:421-426

Jędryka-Góral A (2003) Immuno-inflammatory processes and atherosclerosis-lessons from SLE (in Polish). Reumatologia 41:48-54

Jędryka-Góral A, Pasierski T, Ząbek J, Widerszal-Bazyl M, Radkiewicz P, Szulczyk GA, Wojciechowska B, Bugajska J (2006) Risk factors for atherosclerosis in healthy employees-a multidisciplinary approach. Eur J Intern Med 17:247-253

Jonsson D, Rosengren A, Dotevall A, Lappas G, Wihelmsen L (1995) Job control, job demand and social support at work in relation to cardiovascular risk factors in MONICA

Kiecolt-Glaser JK, Glaser R (1991) Stress and immune function in humans. In: Ader R, Felten DL, Cohen N (eds) Psychoneuroimmunology, Academic Press, San Diego

Kivimaki M, Leino-Arjas P, Luukkonen R, Riihimak H, Vahtera J, Kirjonen J (2002) Work stress and risk of cardiovascular mortality: prospective cohort study of industrial employees. BMJ 325:857-860
Kivimaki M, Ferrie JE, Brunner E, Head J, Shipley MJ, Vahtera J, Marmot MG (2005) Justice at work and reduced risk of coronary heart disease among employees: the Whitehall II study. Arch Intern Med 165:2245-2251

Kristenson M, Kucinskiene Z, Bergdahi B, Calkouskas H, Urmonas V, Orth-Gomer K (1998) Increased psychosocial strain in Lithuanian versus Swedish men: the LiVicordia study. Psychosom Med 60:277-282

Lindgren T, Andersson K, Dammstrom BG, Norback D (2002) Occular, nasal, dermal and general symptoms among commercial airline crews. Int Arch Occup Environ Health 75:475-483

Luft S, Frączek D, Jędryka-Góral A, Małdykowa H (1990) Studies on prevalence of anticardiolipin antibodies in patients with connective tissue diseases (in Polish). Reumatologia 28:161-169

Lynch J, Krause N, Kaplan GA, Salonen R, Salonen JT (1997) Workplace demands, economic reward, and progression of carotid atherosclerosis. Circulation 96:302-307

Malinauskiene V, Theorell T, Grazuleviciene R, Azaraviciene A, Obelenis V, Azalis V (2005) Psychosocial factors at work and myocardial infarction among men in Kauns, Lithuania. Scand J Work Environ Health 31:218-223

Nordstrom CK, Duryer KM, Merz NB, Shircore A, Duryer JH (2001) Work-related stress and early atherosclerosis. Epidemiology 12:180-185

Rosengren A, Hawken S, Ounpuu S, Sliwa K, Zubaid M, Almahmeed WA, Blackett KN, Sitthi-amorn C, Sato H, Yusuf S, INTERHEART investigators (2004) Association of psychosocial risk factors with risk of acute myocardial infarction in 11119 cases and 13648 controls from 52 countries (the INTERHEART study): case-control study. Lancet 364:953-962

Rosvall M, Ostergren PO, Hedblad B, Iscsson SO, Janzon L, Berglund G (2002) Work-related psychosocial factors and carotid atherosclerosis. Int J Epidemiol 31:1169-1178

Pasierski T (1999) Mysteries of initials of the atherosclerotic process news coming from the PDAY study (in Polish). Jama 10:706-707

Patryka L, Hartwich J, Kiec-Wilk B, Polus A, Wybranska I, Dembinska-Kiec A (2001) Is atherosclerosis an autoimmunological process? Przegl Lek 58:1067-1070

Pignoli P, Tremoli E, Poli A, Oreste P, Paoletti R (1986) Intimal plus medial thickness of the arterial wall: a direct measurement with ultrasound imaging. Circulation 74:1399-1406

Smith LA, Roman A, Dollard MF, Wienfield AH, Siegrist J (2005) Effort-reward imbalance at work: the effects of work stress on anger and cardiovascular disease symptoms in a community sample. Stress Health 21:113-128

Toobert DJ, Strycker LA, Glasgow RE, Barrera M, Bagdade JD (2002) Enhancing support for helath behavior change among women at risk for heart disease: the mediteranean lifestyle trial. Health Educ Res 17:574-585

Tsoulfa G, Rook GAW, Bahr GM, Sattar MA, Behehani K, Young DB, Mehlert A, Van-Embden JD, Hay FC, Isenberg DA (1989) Elevated IgG antibodies to the mycobacterial $65 \mathrm{kDa}$ heat shock protein are characteristic of patients with rheumatoid arthritis. Scand J Immunol 30:519-527

Weidner G, Cain VS (2003) The gender gap in heart disease: lessons from Eastern Europe. Am J Pub Health 93:768-770

Widerszal-Bazyl M (2001) Stress at work. polish adaptation of occupational stress indicator-OSI-2 (in Polish). CIOP, Warszawa

Ursin H, Eriksen HR (2004) The cognitive activation theory of stress. Psychoneuroendocrinology 29:567-592

Eriksen HR, Murison R, Pensgaard AM, Ursin H (2005) Cognitive activation theory of stress (CATS): from fish brains to the Olympics. Psychoneuroendocrinology 30:933-938 